\title{
DISPOSIÇÃO A PAGAR PELA TAXA DE TURISMO DO CONVENTION \& VISITORS BUREAU EM HOTÉIS DE CURITIBA ${ }^{1}$
}

\author{
Willingness to pay the Convention \& Visitors Bureau \\ tourism tax in Curitiba's hotels
}

\footnotetext{
Iomara Scandelari Lemos ${ }^{[a]}$, José Roberto Frega ${ }^{[\mathrm{b}]}$, Alceu Souza ${ }^{[\mathrm{c}]}$, Wesley Vieira da Silva ${ }^{[\mathrm{d}]}$

[a] Doutoranda em Administração do Programa de Pós-Graduação em Administração da Pontifícia Universidade Católica do Paraná (PUCPR), Curitiba, PR - Brasil, e-mail: iomara.lemos@gmail.com

${ }^{[b]}$ Doutorando em Administração do Programa de Pós-Graduação em Administração da Pontifícia Universidade Católica do Paraná (PUCPR), Curitiba, PR - Brasil, e-mail: jose.frega@gmail.com

[c] Doutor em Administração, professor adjunto do Programa de Pós-Graduação em Administração da Pontifícia Universidade Católica do Paraná (PUCPR), Curitiba, PR - Brasil, e-mail: alceu.souza@pucpr.br

[d] Doutor em Engenharia de Produção, professor adjunto do Programa de Pós-Graduação em Administração da Pontifícia Universidade Católica do Paraná (PUCPR), Curitiba, PR - Brasil, e-mail: wesley.vieira@pucpr.br
}

\begin{abstract}
Resumo
A taxa municipal de turismo é cobrada em hotéis de diversas cidades no mundo, e as receitas geradas por ela são usadas para melhorias e desenvolvimento do turismo no local. Este artigo avalia a disposição a pagar a taxa de turismo cobrada àqueles que se hospedam nos hotéis da cidade de Curitiba. A pesquisa é quantitativa, exploratória e descritiva, usando o método de valoração contingente com técnica para obtenção da disposição a pagar dos turistas de escolha dicotômica ou referendum, visando a determinar o valor econômico para os recursos utilizados pelo turista. No estudo observa-se que a maior parte dos visitantes não apresenta disposição a pagar a taxa de turismo. Como resultados, percebeu-se que há menor disposição para pagar quanto maior o valor da taxa de turismo, quanto mais baixa a classe econômica e quanto maior o nível de escolaridade dos turistas.
\end{abstract}

Palavras-chave: Disposição a pagar. Taxa de turismo. Hotelaria curitibana. Desenvolvimento turístico municipal.

\section{Abstract}

Municipal tourism tax is charged in various hotels in cities around the world, and the generated incomes are used for improvement and development of the local tourism. This paper evaluates the willingness to pay (WTP)

\footnotetext{
1 Artigo apresentado no Seminário Internacional de Turismo. Curitiba: OBSTUR/UFP; Universidade Positivo, 2009.
} 
the tourism tax which is charged to whom stays in hotels in the city of Curitiba. The research is quantitative, exploratory and descriptive, using the contingent valuation method with dichotomical or referendum techniques to obtain the WTP of the tourists. In the research, is observed that the majority of the respondents do not have WTP the tourism tax. Some results point to that there is less WTP as grows the amount to be paid for the tax or grows the scholarly level of the respondent and as the socioeconomic level of the respondent goes down.

Keywords: Willingness to pay. Tourism tax. Hotels in Curitiba. Municipal tourism development.

\section{INTRODUÇÃO}

O objetivo do presente trabalho é avaliar a disposição dos turistas a pagar a taxa de turismo cobrada em diversos hotéis de Curitiba durante a hospedagem e estadia na cidade. Trata-se de uma pesquisa quantitativa, exploratória e descritiva, baseada no método de valoração contingente com técnica para obtenção da disposição a pagar (DAP) dos turistas calcada na escolha dicotômica ou referendum. Assim, pode-se determinar valor econômico para os recursos utilizados pelo turista.

Este estudo de caso foi realizado em Curitiba, no Estado do Paraná, pois a cidade já apresenta valores determinados pela prefeitura para a cobrança de taxa de turismo. Essa taxa é cobrada por dia de hospedagem em mais de 600 cidades ao redor do mundo e os recursos são utilizados para melhorias e desenvolvimento do turismo no município. Em Curitiba, a taxa de turismo, ou room tax, é cobrada desde agosto de 2001 pelo Curitiba Convention \& Visitors Bureau (CCVB) e os valores variam de acordo com a categoria do hotel. Segundo o CCVB (2006), são quatro categorias: $\mathrm{R} \$ 0,50, \mathrm{R} \$$ $1,00, R \$ 1,50$ e $R \$ 2,00$ para os hotéis de duas, três, quatro e cinco estrelas, respectivamente.

Em Curitiba, os hotéis não são obrigados a cobrar essa taxa. Em geral, aqueles vinculados ao CCVB é que o fazem. Em tese, o valor deveria ser cobrado por dia de hospedagem, mas na prática muitos hotéis cobram menos, pois percebem, intuitivamente, que muitos hóspedes não querem pagar por ela.

Conforme o CCVB (2006), os valores arrecadados pela room tax são para promoção do destino Curitiba. Essa taxa é aplicada em benefícios aos turistas e apoio gratuito a entidades interessadas em fazer eventos na capital. OCCVB disponibiliza mapas com roteiros dos principais atrativos turísticos, bem como informações úteis e a principal programação cultural da cidade. Também administra, em conjunto com o Instituto Municipal de Curitiba, o Posto Informações Turísticas da Rua 24 Horas. O CCVB apoia gratuitamente as entidades interessadas em realizar seus eventos na capital e auxilia nas ações de promoção de Curitiba - envolvendo a criação, a elaboração e a confecção de biddings books (propostas de candidatura para que Curitiba seja sede de eventos).

De acordo com o CCVB (2006), os principais investimentos realizados atualmente com a arrecadação da taxa de turismo são: captação e apoio a mais de 300 eventos, visando ao incremento no fluxo de turistas por meio da realização e ampliação do número de eventos; confecção de mais de 500 mil mapas de Curitiba distribuídos gratuitamente nos postos de informações turísticas montados nos eventos; instalação de postos de informações turísticas em todos os eventos apoiados pelo CCVB, entre outros.

Dessa forma, intencionou-se averiguar a disposição do turista a pagar o valor que já é proposto, bem como verificar a disposição a pagar uma taxa um pouco mais elevada. Vale destacar que a DAP por parte dos turistas que visitam Curitiba revela, por meio de sua escala de utilidade marginal, a melhor estimativa de sua escala de demanda, o que possibilita a elaboração do cálculo das medidas de bem-estar. Neste contexto procura-se, à luz desse método, simular diferentes cenários alternativos cujas características encontram-se o mais próximo possível dos existentes no mundo real, de tal forma que as preferências verdadeiras dos turistas sejam expressas em valores monetários.

Este trabalho encontra-se estruturado em seções que podem ser assim sumarizadas: a primeira refere-se à parte introdutória; a segunda trata do referencial teórico sobre o método de disposição a pagar (DAP), que dá suporte à pesquisa; a terceira diz respeito à metodologia da pesquisa; a quarta refere-se à apresentação e análise dos dados; e a quinta trata 
das considerações finais e recomendações para a elaboração de trabalhos futuros.

\section{O método de disposição a pagar (DAP)}

$\mathrm{Na}$ teoria microeconômica neoclássica, as preferências dos indivíduos são captadas pela disposição a pagar por um determinado bem ou serviço. A decisão dos indivíduos de pagar valores monetários por certos bens e não pagar por outros carrega consigo as preferências individuais, as motivações e a busca de maximização do bem-estar individual. Assim, a DAP depende principalmente de como cada indivíduo avalia os benefícios conseguidos com o produto adquirido ou serviço prestado. Ela é influenciada pela experiência pessoal de cada um.

Os métodos de valoração econômica são instrumentos analíticos com aplicações que se expandiram de recreação ao ar livre para bens públicos, tais como vida selvagem, qualidade do ar, saúde humana e estética (HANLEY; SPASH, 1993, p. 4). Esses autores afirmam que a aplicação desses métodos sem a compreensão dos fundamentos teóricos cria uma "falsa impressão da robustez dos resultados".

Esses métodos de valoração são caracterizados como técnicas específicas para quantificar em termos monetários os impactos econômicos e sociais de projetos. Tais resultados numéricos vão permitir uma análise mais abrangente desses impactos. De posse dos resultados expressos na mesma unidade de medida (unidades monetárias), pode-se fazer uma avaliação da preponderância de um ou de outro fator (benefícios ou custos) e ter subsídios para escolher a melhor opção a ser tomada.

Vale salientar que as bases intelectuais para os procedimentos reportados anteriormente encontram-se na teoria neoclássica e na economia do bem-estar (HUFSCHMIDT et al., 1983), sendo utilizados para estimar os valores que as pessoas atribuem aos recursos ambientais, pautando-se nas suas preferências individuais.

A literatura econômica tradicional sugere que o valor de um bem ou serviço pode ser mensurado por meio da preferência individual pela preservação, conservação ou utilização desse bem ou serviço (BATEMAN; TURNER, 1992). Considerando o gosto e/ou as preferências de cada agente econômico, este tem um conjunto de preferências que é usado na valoração de todo e qualquer bem ou serviço.
Considera-se como hipótese fundamental para o uso dessa metodologia o fato de o comportamento do agente econômico ser racional em termos agregados. Tal racionalidade significa que as decisões do agente econômico maximizam a utilidade proporcionada pelo consumo de bens e serviços. Ademais, a utilidade pode ser traduzida pela satisfação individual proveniente de consumir determinada quantidade de produtos e/ou serviços e, adicionalmente, essa satisfação se reduz à medida que maiores quantidades de produtos ou serviços são consumidas. Isso é o que os economistas denominam de Utilidade Marginal Decrescente e o que confere uma inclinação negativa da curva de demanda de mercado (agregada).

Young e Fausto (2006) avaliam o valor econômico na literatura e afirmam que tem sido apresentado como: valor econômico total $=$ valor de uso + valor de opção + valor de existência. $\mathrm{O}$ valor de uso representa o valor atribuído pelas pessoas pelo uso ou usufruto dos recursos. Esses mesmos autores mostram que o valor de uso é composto pelo valor de uso direto, em que o indivíduo usufrui no momento atual de um recurso, e pelo valor de uso indireto, no qual o benefício atual do recurso é derivado de funções ecossistêmicas como, por exemplo, a proteção dos corpos d'água decorrente da preservação das florestas.

Dentro deste contexto, esses mesmos autores também comentam que mesmo aquelas pessoas que não usufruem atualmente de serviços prestados podem também atribuir-lhe um valor. Trata-se de um valor relacionado a usos futuros que podem gerar alguma forma de benefício ou satisfação aos indivíduos. Este valor é referido como valor de opção, ou seja, opção para uso futuro - direto ou indireto - em vez do uso presente conforme for compreendido no valor de uso. Para Martins e Peres (2005), o valor de opção é caracterizado como a disposição a pagar dos indivíduos pela preservação ou manutenção das características atuais de um determinado recurso, para o futuro.

A terceira parcela refere-se ao valor de existência, caracteriza-se como um valor de não uso (YOUNG; FAUSTO, 2006). Essa parcela é a mais difícil de conceituar, uma vez que se refere à manutenção da existência do recurso independentemente da atribuição de uso no presente ou no futuro.

O método de valoração contingente foi originalmente proposto no ano de 1963, num artigo 
descrito por R. Davis relacionado à economia e recreação. A base teórica desse método está nas preferências do consumidor, por meio da função utilidade individual. Nas décadas de 70 e 80 houve um desenvolvimento acentuado dessa técnica nos Estados Unidos, tornando-a bastante utilizada por parte dos economistas (HANLEY; SPASH, 1993).

A mensuração do valor econômico a partir das funções de utilidade pode ser feita tomando os conceitos de DAP e disposição a receber compensação (DAC) e/ou por meio de medidas de excedente do consumidor (marshalliana) ou medidas de compensação (bicksianas). O método de valoração contingente busca extrair a DAP ou a DAC por uma modificação no nível do fluxo do serviço ambiental de uma amostra de consumidores a partir de questionamento direto, supondo um mercado hipotético cuidadosamente estruturado. Baseando-se nessas medidas de DAP, em princípio, é possível estimar as medidas bicksianas de acordo com as peculiaridades do recurso ambiental objeto de valoração e obter também a curva de demanda de mercado pelo bem ou serviço.

A operacionalização do método de valoração contingente ocorre a partir da aplicação de questionários elaborados de forma cuidadosa visando a obter dos entrevistados os valores da DAP ou a aceitar uma compensação (DAC) (PEARCE, 1993). Notadamente, após a aplicação desses questionários os resultados são tabulados e submetidos a uma análise econométrica, de forma a derivar valores médios dos lances da DAP ou DAC.

O método de avaliação contingente não apresenta uma forma padrão definida a priori (MARTINS, 2002); varia de acordo com a natureza do bem avaliado, restrições teóricas e metodológicas, imaginação e engenhosidade do pesquisador. Para permitir a obtenção de dados confiáveis, a pesquisa tem que definir e familiarizar os entrevistados com:

a) nível de utilidade de referência;

b) natureza do bem público;

c) relevância dos preços de outros bens;

d) condições para provisão do bem e forma de pagamento;

e) natureza do valor da disposição a pagar pretendida (MARTINS, 2002).

O nível de utilidade de referência leva em consideração a restrição orçamentária do entrevistado e os direitos de propriedade sobre o bem público.
A natureza do bem público avaliado leva em conta o conhecimento das características desse por parte do consumidor. A relevância dos preços de outros bens pode afetar a disposição a pagar. As condições para provisão e a forma de pagamento do bem são esclarecidas no cabeçalho do questionário aplicado. Por fim, chega-se à abordagem direta sobre um valor que o entrevistado está disposto a pagar.

Existem dois métodos utilizados mais amplamente para obter a disposição máxima a pagar. O primeiro apresenta questões abertas (open-ended) e consiste em perguntar o valor máximo que estaria disposto a pagar. No entanto, neste caso corre-se o risco de produzir inúmeras não respostas e valores nulos graças à dificuldade do consumidor em decidir por um valor. O segundo utiliza-se de questões fechadas (closed-ended), primeiramente especificando um valor determinado e perguntando ao entrevistado se estaria ou não disposto a pagar aquele valor referido.

Todavia, o reconhecimento de valor de um destino turístico está ligado intimamente ao envolvimento que o turista adquire com o local. O envolvimento refere-se ao grau em que um produto está voltado ao valor; quanto mais ligado à autoimagem da pessoa, mais envolvido o turista estará no processo de valoração. Em geral, um alto envolvimento refere-se a produtos e serviços que refletem o status social do indivíduo, seu estilo de vida, a participação no grupo referência, ou está vinculado a seus conceitos, crenças e referenciais de valor. Por outro lado, os produtos de baixo envolvimento são aqueles de natureza menos simbólica e que tendem a servir de funções utilitárias bastante comuns; desta forma, não se representam como bens valiosos. As viagens de férias são produtos que têm alto valor simbólico e tendem a despertar alto envolvimento.

A disposição a pagar é ligada, também, ao sentido de utilidade do bem turístico. Para Bentham (1979), a natureza colocou o homem sob o domínio da dor e do prazer. Estes sentimentos levam o ser humano a agir segundo o princípio da utilidade, que consiste em caminhar rumo à felicidade, baseado na razão e na lei. Tal princípio aprova ou desaprova qualquer ação conforme sua tendência em aumentar ou diminuir a felicidade da pessoa. Porém, o princípio não está ligado somente aos indivíduos, senão faz alusão à comunidade e ao bem que pode gerar a este grupo de indivíduos.

Segundo Lemos (2005, p. 93), "a utilidade encontrada ao ter saciedade de um bem é individual 
e efêmera". Conforme ressalta esse mesmo autor, nem toda utilidade individual é socialmente necessária, ética e responsável. Por outro lado, a substância social do valor turístico, quando assume a forma transitória de mercadoria, tem uma amplitude maior do que o somatório de matérias-primas, trabalho, máquinas e tecnologias imbricadas em um processo de mercadorias em uma empresa de determinada indústria (LEMOS, 2005, p. 93).

Percebe-se que o valor turístico extrapola o conceito clássico, pois é constituído de bens individuais e coletivos e de relacionamento humano. Neste sentido, incorpora o sistema turístico definido por Beni (2003) com seus três conjuntos: das relações ambientais (ecológico, social, econômico e cultural), da organização estrutural (infraestrutura e superestrutura) e o conjunto das ações operacionais (produção, consumo e distribuição). Mas também recebe a influência das pessoas e dos acontecimentos externos ao sistema. Assim, se o conjunto não estiver integrado de forma que se percebam as qualidades do destino, ele pode perder valor. Lemos (2005, p. 94) afirma que "o valor turístico - para ser valor turístico - requer a existência de um processo de agregação, e não de desagregação". Para ele, o sistema e o turista são elementos que agregam ou desagregam o valor turístico.

Considerando outros elementos que afetam a disposição a pagar, deve-se levar em conta, ainda, que muitos destinos turísticos têm características de bens não exclusivos. Para Gonzalez (2004, p. 4), "[...] ocorre não exclusividade quando é impossível impedir que uma pessoa se beneficie de um bem ou serviço". Para Pindyck e Rubinfeld (1994), o bem é não excludente não somente quando for impossível impedir aos outros de consumi-lo, mas também quando for muito caro fazê-lo.

A ausência de exclusão dificulta um mecanismo de cobrança pelo uso. Estes tipos de bens são aqueles que a sociedade reconhece como acessíveis à população, portanto livres das influências do mercado. Dentre os bens não exclusivos estão os serviços públicos. Os serviços públicos são aqueles que atendem à sociedade de uma localidade específica (população de município, Estado, País), satisfazendo as necessidades individuais. Os serviços públicos são considerados "direitos" constitucionais de todas as pessoas; sua manutenção é realizada pelos governos municipais, estaduais, governos federais, mediante o pagamento dos impostos e taxas. Todavia, não parece correto que somente os cidadãos arquem com a manutenção dos bens públicos destinados, também, aos turistas; portanto “[...] faz-se necessário que os governos municipal, estadual e federal arbitrem políticas em colaboração com o setor privado que proporcionem oportunidades de investimentos e melhorias do produto, bem como desenvolvimento local" (LEMOS; FREGA; SOUZA, 2007, p. 41), como a taxa de turismo.

Deve-se ressaltar que as pesquisas de disposição a pagar têm aplicação como alternativa para a obtenção do preço médio que poderia ser pago pelos consumidores finais. Assim, esta pesquisa de disposição a pagar configura-se como um referencial a indicar qual o repasse aceito pelos turistas em troca do que lhes é oferecido na cidade de Curitiba.

\section{METODOLOGIA DA PESQUISA}

A pesquisa realizada classifica-se, quanto ao nível, como exploratória e descritiva. É descritiva porque avalia os aspectos pesquisados que influenciaram na disposição a pagar e descreve quanto o valor da taxa influenciou na disposição a pagar e a relação entre as variáveis. É exploratória, pois proporciona maior familiaridade com o problema com vistas a torná-lo explícito ou a construir hipóteses, permitindo ao investigador aumentar sua experiência em torno de determinado problema, e desenvolver, esclarecer e modificar conceitos eideias (TRIVIÑOS, 1987; GIL, 1999).

Do ponto de vista da forma de análise a pesquisa é quantitativa, pois traduz em números opiniões e informações para classificá-las e analisálas e também requer o uso de recursos e de técnicas estatísticas (GIL, 1999). Em termos de técnicas e procedimentos, foi aplicado um questionário em uma amostra de pessoas que tiveram experiências práticas com o problema pesquisado. O formato da pesquisa é de um estudo de valoração contingente.

\section{HIPÓTESES A SEREM TESTADAS}

Segundo Lakatos e Marconi (2000), as pesquisas exploratórias objetivam a formulação de questões ou de um problema e têm tripla finalidade: desenvolver hipóteses, aumentar a familiaridade do pesquisador com um ambiente, fato ou fenômeno, 
para a realização de uma pesquisa futura mais precisa ou modificar e clarificar conceitos. É a primeira etapa de uma investigação mais ampla. Em se tratando de pesquisa exploratória, foram elaboradas as seguintes hipóteses a serem testadas:

- $\mathrm{H}_{1}$ : espera-se que a relação entre o valor da taxa e a disposição a pagar seja negativa. Dessa forma, quanto maior o valor da taxa, menor disposição a pagar;

- $\mathrm{H}_{2}$ : espera-se que a relação entre o Critério Brasil e a disposição a pagar seja negativa. Assim, quanto mais baixa a classe social, acredita-se que seja menor a disposição a pagar;

- $\mathrm{H}_{3}$ : espera-se que a relação entre a escolaridade e a disposição a pagar seja positiva, ou seja, quanto maior o nível de escolaridade, maior a disposição a pagar por parte dos turistas.

\section{Método de análise}

O método de valoração contingente procura determinar as preferências dos indivíduos por bens públicos, por meio da determinação da disposição a pagar destes indivíduos por melhorias na provisão destes bens, ou por meio da disposição a aceitar compensação por uma eventual perda de utilidade destes bens. Assim, esta técnica baseia-se em dois conceitos fundamentais, que são indicadores monetários de preferências, quais sejam: disposição a pagar (willingness to pay) e disposição a aceitar (willingness to accept) compensação (MARTINS, 2002, p. 62).

Neste trabalho utiliza-se a técnica de referendum ou escolha dicotômica. Neste caso, usa-se um número de valores predeterminados, baseados no valor monetário já cobrado, que darão origem ao valor monetário esperado da disposição a pagar. Nesta técnica, os valores são apresentados aleatoriamente ao entrevistado; a cada entrevistado é apresentado apenas um valor ao qual ele deve responder "sim" ou "não" com respeito à disposição a pagar. Ao responder, o consumidor não tem outra chance de escolher novo valor. A quantia é modificada ao longo da amostra verificando-se a frequência das respostas.

\section{PROCESSO DE AMOSTRAGEM}

Para a pesquisa foram abordados 200 turistas, dos quais resultaram 185 questionários válidos. As entrevistas pessoais foram aplicadas em 15 hotéis de Curitiba, com auxílio dos discentes do curso de Turismo das faculdades SPEI, Curitiba, PR. O formato do questionário foi composto de seis partes. Dentre os hotéis onde a pesquisa foi aplicada constatou-se que nove cobram a taxa de turismo, enquanto seis não cobram; porém nos que não cobram a taxa foram obtidos somente 30 respondentes. Antes de construir o modelo, verificou-se que o padrão de acertos do modelo era consistente ao longo dos hotéis, menos em um, do qual foram excluídas as respostas. A amostra de hotéis foi uma amostra estratificada, cujos estratos representam as diversas categorias que cobram taxa de turismo, considerando os 42 hotéis que fazem parte do Curitiba Convention \& Visitors Bureau.

O processo de entrevista pessoal apresentou cinco partes. A primeira parte do questionário foi composta pelo cabeçalho que esclarece sobre a pesquisa e sobre a cobrança da taxa de turismo em Curitiba e suas finalidades. A segunda parte coleta informações a respeito da viagem realizada. A terceira levanta informações socioeconômicas do entrevistado. A quarta parte verifica se o turista está na localidade para primeira vez ou se já esteve outras vezes. A quinta parte questiona sobre a disposição a pagar. A parte final verifica a vontade de retorno ao destino em uma próxima viagem.

Embora a taxa de turismo cobrada atualmente em Curitiba varie de $\mathrm{R} \$ 0,50$ a $\mathrm{R} \$ 2,00$, foram incorporados outros valores. Desta forma, foram sugeridos sete estratos de preços ( $\mathrm{R} \$ 0,50$, $\mathrm{R} \$ 1,00, \mathrm{R} \$ 1,50, \mathrm{R} \$ 2,00, \mathrm{R} \$ 3,00, \mathrm{R} \$ 4,00$ e $\mathrm{R} \$$ $5,00)$ nos questionários, a fim de verificar se existe a disposição a pagar um pouco mais pela taxa de turismo de Curitiba.

\section{APRESENTAÇÃO E ANÁLISE DOS DADOS}

No estudo de caso da taxa de turismo de Curitiba, dos 185 questionários válidos, 58 apresentaram disposição a pagar. A estatística qui-quadrado encontra-se na Tabela 1 , e apresenta um resultado $\chi^{2}(6)=0,518907$, correspondendo a um nível de 
significância de 0,9976, o que não permite rejeitar a hipótese nula de uniformidade das frequências das classes, correspondendo a aproximadamente 14\% dos respondentes para cada faixa. Não há indícios de diferenças significativas entre as categorias, não se fazendo necessário desprezar nenhum caso dentre os questionários válidos.

Realizou-se um cruzamento das variáveis independentes valor da taxa de turismo, escolaridade, idade e Critério Brasil (Critério de Classificação Econômica Brasil, da Associação Brasileira de Empresas de Pesquisa - ABEP, 2003) (conforme escalas de valores na Tabela 1), em busca de relações significantes, tendo como variável dicotômica dependente a DAP. Para tanto, com auxílio do software SPSS ${ }^{\circledR}$, realizou-se correlação de Pearson e uma regressão logística binária utilizando o Método Enter. O método Enter coloca todas as variáveis independentes no modelo e deixa a critério do pesquisador utilizar aquelas que sejam significantes e/ ou tenham um fundamento teórico ou metodológico. A intenção da regressão é melhorar o modelo nulo, que é o índice de acerto natural decorrente da ausência de um modelo formal. Cabe lembrar que o questionário apresenta elementos paramétricos e não paramétricos. Com isso, foi gerado um modelo que apresentou um pseudo- $\mathrm{R}^{2}$ de 0,276. O R $\mathrm{R}^{2}$ de Nagelkerke é similar ao $\mathrm{R}^{2}$ da regressão linear, significando a variância explicada da variável dependente por meio das independentes.

Tabela 1 - Escala de medida das variáveis

\begin{tabular}{|c|c|c|}
\hline VARIÁVEIS & DESCRIÇÃO & ESCALA \\
\hline \multirow{5}{*}{ Escolaridade } & analfabeto $/ 1^{\mathrm{a}}$ a $4^{\mathrm{a}}$ séries completas & 0 \\
\hline & $1^{\mathrm{a}}$ a $4^{\mathrm{a}}$ séries completas & 1 \\
\hline & $5^{\mathrm{a}}$ a $8^{\mathrm{a}}$ séries completas & 2 \\
\hline & $2^{\circ}$ grau completo & 3 \\
\hline & superior completo & 4 \\
\hline \multirow{4}{*}{ Idade } & menos de 20 anos & 1 \\
\hline & 20 a 40 anos & 2 \\
\hline & 40 a 60 anos & 3 \\
\hline & mais de 60 anos & 4 \\
\hline \multirow{7}{*}{ Critério Brasil } & A1 & 1 \\
\hline & $\mathrm{A} 2$ & 2 \\
\hline & B1 & 3 \\
\hline & B2 & 4 \\
\hline & $\mathrm{C}$ & 5 \\
\hline & $\mathrm{D}$ & 6 \\
\hline & $\mathrm{E}$ & 7 \\
\hline \multirow{7}{*}{ Valor da taxa de turismo } & $\mathrm{R} \$ 0,50$ & 1 \\
\hline & $\mathrm{R} \$ 1,00$ & 2 \\
\hline & $\mathrm{R} \$ 1,50$ & 3 \\
\hline & $\mathrm{R} \$ 2,00$ & 4 \\
\hline & $\mathrm{R} \$ 3,00$ & 5 \\
\hline & $\mathrm{R} \$ 4,00$ & 6 \\
\hline & $\mathrm{R} \$ 5,00$ & 7 \\
\hline
\end{tabular}

Tabela 2 - Correlação de Pearson para escolaridade, idade e Critério Brasil

\begin{tabular}{lllrr}
\hline & & Escolaridade & Idade & Critério Brasil \\
\hline \multirow{2}{*}{ Escolaridade } & Correl. Pearson & 1 & 0,01 & $-0,45^{* * *}$ \\
\multirow{2}{*}{ Idade } & Signific. Bicaudal & - & 0,91 & 0,00 \\
& Correl. Pearson & 0,01 & 1 & $-0,03$ \\
\multirow{2}{*}{ Critério Brasil } & Signific. Bicaudal & 0,91 & - & 0,73 \\
& Correl. Pearson & $-0,45^{* * *}$ & $-0,03$ & 1 \\
& Signific. Bicaudal & 0,00 & 0,73 & - \\
\hline
\end{tabular}

** Correlação significante a 0,001\%. 
Ao efetuar a correlação de Pearson, percebeu-se que o Critério Brasil está negativamente relacionado com a escolaridade, ou seja, quanto maior a escolaridade, maior a faixa de renda, então, menor o Critério Brasil (Tabela 2).
A regressão logística gerou um modelo cuja especificação está na Tabela 3 e sua formulação, na qual $\pi$ é a probabilidade de um indivíduo apresentar disposição a pagar a taxa de turismo, é:

$$
\begin{aligned}
& \pi(\text { Pagar })=f(\text { Escolaridade, Critério Brasil, Valor da Taxa })=f(y)=\frac{1}{1+e^{-y}} \\
& \text { onde } \\
& y=3,50-0,77 \times \text { Escolaridade }-0,34 \times \text { Critério Brasil - 0,48 XValor da Taxa }
\end{aligned}
$$

Enquanto o modelo nulo apresentava um acerto de $68,6 \%$, numa população da qual não se sabe nada a respeito do respondente, com o modelo logístico melhorou-se este índice para 71,4\%. Esta melhora é pequena e pouco significativa, pois para melhorar o acerto entre os dispostos a pagar pioraram os acertos entre os não dispostos a pagar pela taxa de turismo.

$\mathrm{Na}$ Tabela 3, os valores erro padrão, Wald e significância exprimem a qualidade de cada uma das variáveis independentes na regressão logística. Quanto menor o erro padrão, maior o coeficiente de Wald e menor a significância, maior o poder de influência que tem a variável independente associada sobre a probabilidade de existir disposição a pagar. A coluna odds ratio apresenta a razão de chance que exprime o incremento de explicação dado pela variável; quanto maior este valor, maior o incremento de explicação da variável associada a ele.
Ainda na Tabela 3 apresentam-se relações negativas entre as variáveis independentes valor da taxa, Critério Brasil e escolaridade com a probabilidade de haver disposição a pagar. Quanto maior a escolaridade, menos o turista está disposto a pagar. Quanto maior o Critério Brasil, o que significa menor poder de compra ou classe econômica mais baixa, menor a disposição a pagar. Quanto maior o valor da taxa, também há menor disposição a pagar. Assim, tanto escolaridade quanto Critério Brasil apresentam sinal negativo, apesar da correlação entre essas variáveis ser negativa. Cabe ressaltarque, enquanto a correlação correspondeà cerca de $20 \%$ da variância (decorrentes de uma correlação de -0,45 entre escolaridade e Critério Brasil, conforme a Tabela 2), os outros $80 \%$ causam efeito tão mais forte que demonstram este efeito no sinal que acompanha os valores. As variáveis gênero e idade não apresentaram significância na regressão logística.

Tabela 3 - Coeficientes das variáveis na equação (1)

\begin{tabular}{cccccc}
\hline & B & Erro Padrão & Wald & Significância & Odds ratio \\
\hline Escolaridade & $-0,77$ & 0,16 & 24,56 & 0,00 & 0,46 \\
Critério Brasil & $-0,34$ & 0,30 & 1,25 & 0,26 & 0,71 \\
Valor da taxa & $-0,48$ & 0,20 & 5,82 & 0,02 & 0,62 \\
Constante & 3,50 & 1,49 & 5,54 & 0,02 & 33,09 \\
\hline
\end{tabular}

Ainda pode-se verificar que quanto maior o odds ratio, mais forte a variável no modelo. Em nenhum dos modelos o odds ratio é maior que 1 . Isso traduz certa indiferença do turista com relação à taxa.

Tabela 4 - Valor da taxa e disposição a pagar

\begin{tabular}{ccccc}
\hline Valor da taxa (R\$) & $\begin{array}{c}\text { Frequência (indivíduos } \\
\text { dispostos a pagar) }\end{array}$ & Porcentagem & $\begin{array}{c}\text { Porcentagem } \\
\text { Acumulada }\end{array}$ & Valor arrecadado estimado (R\$) \\
\hline 0,50 & 16 & 27,59 & 27,59 & 8,00 \\
1,00 & 13 & 22,41 & 50,00 & 13,00 \\
1,50 & 10 & 17,24 & 67,24 & 15,00 \\
2,00 & 10 & 17,24 & 84,48 & 20,00 \\
3,00 & 7 & 12,07 & 96,55 & 8,00 \\
4,00 & 2 & 3,45 & 100,00 & 8,00 \\
5,00 & 0 & 0,00 & 100,00 & 0,00 \\
Total & 58 & 100,00 & & \\
\hline
\end{tabular}


Verificou-se com a pesquisa (Tabela 4) que, dentre os pesquisados dispostos a pagar, o ponto de indiferença da disposição a pagar está no valor de $\mathrm{R} \$ 1,00$ com $\mathrm{p}=50 \%$, ou seja, a mediana do valor da taxa de turismo para este caso é $\mathrm{R} \$$ 1,00 - ou seja, até este valor está situada a metade dos pesquisados dispostos a pagar. Acima de R $\$$ 1,00, aumenta o número de não dispostos a pagar. Assim, para uma ação de cobrança de taxa de turismo acima de $\mathrm{R} \$ 1,00$, faz-se necessário um estudo mais aprofundado.

Para a entidade arrecadadora da taxa de turismo, o que interessa é a receita total obtida e não a receita marginal. Em essência, muito mais importante que o aumento da base arrecadatória (número de pagantes da taxa), a qual aumenta com a diminuição do valor da taxa de turismo, é a maximização da receita total, que é o resultado do produto do valor da taxa pelo número de pagantes.

Embora menos pessoas paguem os valores acima de $\mathrm{R} \$ 1,00$, o ponto ótimo de arrecadação na amostra estudada, segundo a Gráfico 1, encontrase no valor da taxa de $R \$ 2,70$. Com os valores de $\mathrm{R} \$ 2,00$ e $\mathrm{R} \$ 3,00$ arrecada-se $\mathrm{R} \$ 20,00$ e $\mathrm{R} \$ 21,00$ respectivamente, em comparação com $\mathrm{R} \$ 13,00$ arrecadados com a cobrança da taxa de $\mathrm{R} \$ 1,00$.

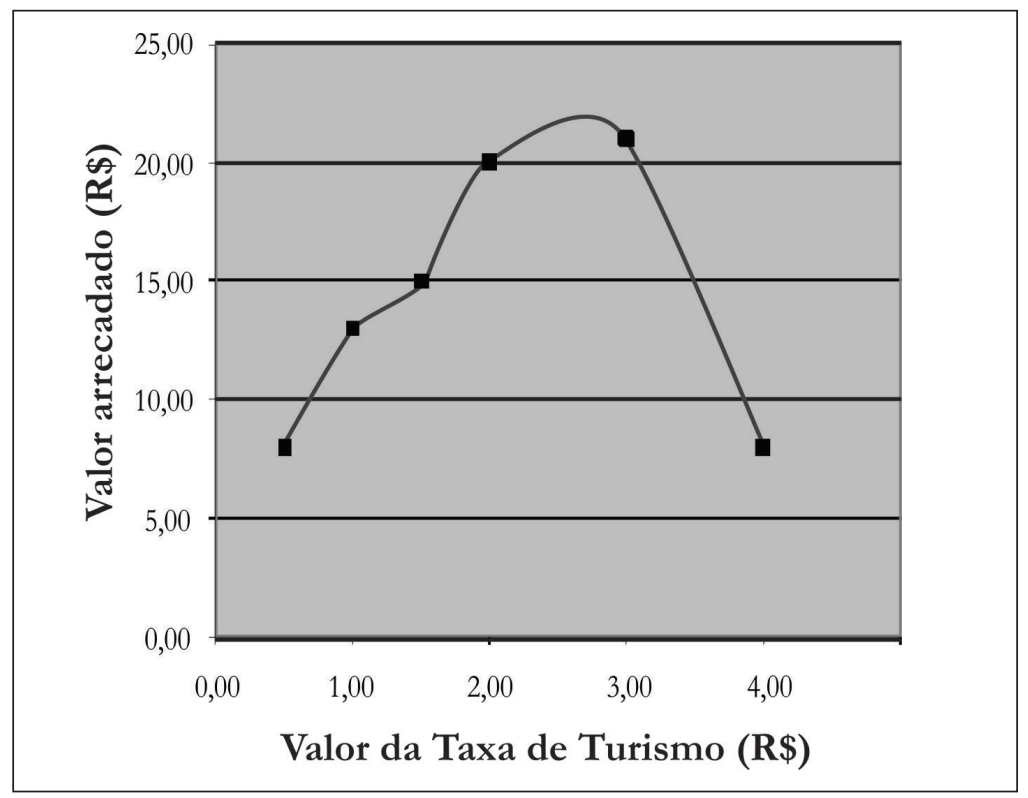

Gráfico 1 - Valores arrecadados pela cobrança da taxa de turismo

\section{EXPERIMENTOS COM O MODELO ENCONTRADO}

Montando um modelo matemático (Equação 2) realizaram-se simulações que demonstram as relações encontradas para responder às hipóteses propostas; as quais se encontram na Tabela 5.

$$
\pi(\text { Pagar })=\frac{1}{1+e^{-(3,50-0,77 \times \text { Escolaridade }-0,34 \times \text { Criterrio Brasil }-0,48 \times \text { Valor da Taxa })}}
$$

$\mathrm{Na}$ primeira simulação, mantendo-se os elementos Critério Brasil e escolaridade num padrão mediano, altera-se o valor da taxa de turismo (casos 1,2 e 3). Percebe-se que quanto maior a taxa, menor a disposição a pagar. Para o valor da taxa de $\mathrm{R} \$ 0,50$ há uma disposição de 65,06\%. Alterando o valor para $\mathrm{R} \$ 2,00$, a disposição cai para $15,67 \%$; quando se troca para $\mathrm{R} \$ 5,00$, a disposição despenca a $1,82 \%$. 
LEMOS, I. S. et al.

Tabela 5 - Modelo encontrado na pesquisa simulando a variação da escolaridade, do Critério Brasil e do valor da taxa de turismo

\begin{tabular}{cccccc}
\hline Simulação & Caso & Escolaridade & Critério Brasil & Valor da taxa & p \\
\hline \multirow{2}{*}{1} & 1 & 2 & 3 & 1 & $65,06 \%$ \\
& 2 & 2 & 3 & 4 & $15,67 \%$ \\
2 & 3 & 2 & 3 & 7 & $1,82 \%$ \\
2 & 4 & 2 & 1 & 3 & $51,10 \%$ \\
& 5 & 2 & 3 & 3 & $28,60 \%$ \\
3 & 6 & 2 & 3 & 3 & $5,60 \%$ \\
& 7 & 0 & 3 & 3 & $43,93 \%$ \\
& 8 & 2 & 3 & 3 & $28,60 \%$ \\
4 & 9 & 4 & 7 & 3 & $17,00 \%$ \\
& 10 & 4 & 1 & 1 & $0,14 \%$ \\
\end{tabular}

$\mathrm{Na}$ segunda simulação, mantendo-se os demais elementos num padrão mediano, nos casos 4, 5 e 6 altera-se somente o Critério Brasil; demonstrase que quanto menor a classe econômica, menor a disposição a pagar. Usando a classe A1, obtém-se disposição a pagar de 51,10\%; passando à classe $\mathrm{B} 1$, a disposição reduz-se para $28,60 \%$; e quando se utiliza a classe $\mathrm{E}$ (hipoteticamente utilizada, pois não houve respondentes nesta classe), cai para $5,60 \%$.

Para a terceira simulação, nos casos 7,8 e 9 utiliza-se um Critério Brasil mediano (classe C), um valor da taxa mediano e varia-se a escolaridade. Para uma baixa escolaridade (até quarta série incompleta), a disposição a pagar é de 43,96\%. Mantendo-se os demais elementos constantes, altera-se a escolaridade para um padrão um pouco maior (primeiro grau completo), e a disposição a pagar cai para $28,60 \%$. Aumentando a escolaridade para superior completo, a disposição a pagar cai ainda mais, chegando a 17\%

Por fim (quarta simulação), simula-se o pior caso (caso 10) e o melhor caso (caso 11) possíveis neste modelo. No pior caso utilizou-se o maior nível de escolaridade, a classe econômica do Critério Brasil mais baixa e o valor da taxa mais alta, obtendo-se uma disposição a pagar de $0,14 \%$. No extremo oposto encontra-se o melhor caso, para o qual se simulou a escolaridade mais baixa (analfabeto), a classe econômica mais alta e o menor valor de taxa de turismo, encontrando-se 90,48\% de disposição a pagar. Porém, é importante ressaltar que esses dois casos extremos são hipotéticos, pois será bastante raro encontrar indivíduos que com quase nenhuma escolaridade tenham conseguido alcançar a classe econômica mais alta. Mais difícil será entrevistar um indivíduo que, com curso superior, tenha uma renda familiar de $\mathrm{R} \$ 207,00$ e, ainda, esteja desfrutando de viagens.

Todavia, o modelo elaborado com os resultados dos questionários aplicados só explica cerca de $27,6 \%$ do comportamento da disposição a pagar (Nagelkerke R Square), o que significa que existem fatores externos aos estudados que influenciam a disposição a pagar que não foram considerados neste estudo, os quais devem ser apreciados em estudo posterior.

\section{CONSIDERAÇÕES FINAIS}

Ao contrário do suposto ao iniciar esta pesquisa, no caso da amostra de hotéis estudados em Curitiba observa-se que a maior parte dos turistas não apresenta disposição a pagar a taxa de turismo.

Quanto às hipóteses levantadas, foram corroboradas as hipóteses $\mathrm{H}_{1}$ (espera-se que a relação entre o valor da taxa e a disposição a pagar seja negativa; desta forma, quanto maior o valor da taxa, menor disposição a pagar) e $\mathrm{H}_{2}$ : (Espera-se que a relação entre o Critério Brasil e a disposição a pagar seja negativa. Assim, quanto mais baixa a classe social acredita-se que seja menor a disposição a pagar). Verificou-se uma relação negativa entre o valor da taxa e a disposição a pagar, quanto maior a taxa menos disposição a pagar. Foi verificado que o ponto de indiferença está no valor de $\mathrm{R} \$ 1,00$, porém o valor da maior arrecadação está em $\mathrm{R} \$$ 2,70 . O estudo apresentou relação negativa entre o Critério Brasil e a disposição a pagar. Lembra-se que o número referente ao Critério Brasil aumenta conforme diminui a classe social do indivíduo; infere-se 
que, quanto mais baixa a classe social, menor foi a disposição a pagar encontrada.

A hipótese $\mathrm{H}_{3}$ (espera-se que a relação entre a escolaridade e a disposição a pagar seja positiva, ou seja, quanto maior o nível de escolaridade, maior a disposição a pagar por parte dos turistas) foi falseada, pois a relação entre a escolaridade e a disposição a pagar foi negativa; ou seja, quanto maior o nível de escolaridade que os turistas possuem, menor a disposição a pagar pela taxa de turismo.

Ao investigar esses elementos, parece que o ocorrido é que o turista é refratário a pagar a taxa de turismo. Não importa muito qual o valor, qual a escolaridade e qual a classe econômica (estabelecida pelo Critério Brasil), fica uma percepção de que:

a) os usuários já pagam demais;

b) não percebem o valor do produto turístico Curitiba;

c) não percebem a utilidade da taxa.

Uma limitação da pesquisa é que esta não objetivou identificar o motivo pelo qual os turistas não estavam dispostos a pagar pela taxa de turismo. Assim, não foi verificado se o turista não enxerga utilidade individual nela, ou apresenta pouco grau de envolvimento, ou são outros fatores que o desmotivam ao pagamento da taxa de turismo.

Comas constatações encontradas, descortinase uma série de hipóteses sobre o número excessivo de turistas não dispostos a pagar a taxa de turismo, que precisam ser confirmadas em pesquisa posterior:

a) a falta de sensação de utilidade provoca menor disposição a pagar. Conforme Bentham (1979), o princípio da utilidade aprova ou desaprova qualquer ação conforme sua tendência em aumentar ou diminuir a felicidade da pessoa e da comunidade. E Curitiba pode não ser percebida como um destino que contribui para esta sensação de felicidade. $O$ fato de a maior parte dos respondentes estar em Curitiba para participar de eventos ou para negócios pode diminuir a sensação de estarem praticando turismo, pois vinculam turismo à ideia de prática de atividades de lazer. Dessa forma, não se sentem desfrutando do que a localidade tem a oferecer e, consequentemente, não há motivação para pagamento da taxa; b) em Curitiba, grande parte dos recursos turísticos tem características de bens não exclusivos pois estão acessíveis a toda a sociedade e livres das influências do mercado. Este fato dificulta a percepção de valor do produto pois representa baixo envolvimento do turista. No caso da disposição a pagar a taxa de turismo, por tratar de bens coletivos, pode estar ocorrendo o comportamento do freerider. Neste tipo de comportamento a pessoa não encontra necessidade em contribuir, somente usufrui. O que move o turista a pensar assim pode ser uma questão como "para que pagar, se todos já estão pagando por isso?”. Como não se trata de um bem exclusivo, fazem-se necessárias outras motivações para o pagamento. Afinal, embora parte dos recursos ofertados aos turistas consista em bens públicos que atendem à população - que os mantém mediante o pagamento dos impostos e taxas-, estes também são usufruídos pelos turistas que não apresentam a percepção de necessidade de pagamento de uma taxa para sua manutenção;

c) os benefícios gerados pela utilização da taxa não são percebidos como algo de valor ao turista, ou realmente não agregam muitos benefícios ao turista. A falta de divulgação dos benefícios advindos da cobrança da taxa pode ser um fator que acarreta a não percepção, uma vez que não se pode perceber aquilo que se desconhece;

d) apesar de perceber valor no turismo e nos recursos dalocalidade, o cidadão brasileiro está cansado de pagar taxas e usufruir pouco delas. Desta forma, não apresenta disposição a pagar taxa alguma, independentemente de a que esta seja destinada. $\mathrm{O}$ turista acredita que o valor pago por outras taxas poderia ser contingenciado para o turismo. O cidadão acredita que já paga suficientemente para a manutenção dos recursos por meio dos impostos e das outras taxas cobradas pelo governo. Os benefícios advindos da taxa são percebidos como ações de responsabilidade do governo municipal e não de entidade privada sustentada por mais uma taxa; 
e) a entidade que cobra a taxa de turismo pode ser vista como mais uma instituição criada para se cobrar mais taxas. Do ponto de vista crítico, o turista pode estar tendo a impressão que uma parte da taxa fica na própria entidade para sua manutenção, não retornando como benefício ao próprio turista.

Este artigo demonstrou que não existe forte disposição a pagar a taxa de turismo na amostra dos hotéis pesquisados em Curitiba, posição observada em $68,6 \%$ dos entrevistados, e indicou que os produtos e serviços oferecidos aos turistas na cidade de Curitiba não apresentam aceitação significativa que justifique o pagamento da taxa de turismo por parte dos usuários. Sugere-se a elaboração de estudos que busquem as fontes dos mais de $70 \%$ da variância não explicada da disposição a pagar (já que o $\mathrm{R}^{2}$ de Nagelkerke da regressão foi igual a 0,276 ) e que possam subsidiar ações que aumentem a sensação de utilidade por parte dos usuários e, desta forma, gerem um ciclo virtuoso no qual os usuários pagam a taxa pois percebem as melhorias e o sistema turístico melhora graças ao bom emprego dos valores arrecadados.

\section{REFERÊNCIAS}

ASSOCIAÇÃO BRASILEIRA DE EMPRESAS DE PESQUISA - ABEP. Critério de classificação econômica Brasil. 2003. Disponível em: <http://www.abep. org >. Acesso em: 15 out. 2006.

BATEMAN, I.; TURNER, K. Valuation of the environment, methods and techniques: the contingent valuation method. Sustainable Environmental Economics and Management, v. 40, n. 4, p. 48-55, 1992.

BENI, M. C. Análise estrutural do turismo. 8. ed. São Paulo: SENAC, 2003.

BENTHAM, J. Uma introdução aos princípios da moral da legislação. 2. ed. São Paulo: Abril, 1979.

CURITIBA CONVENTION \& VISITORS BUREAU CCVB. Taxa de Turismo: inédito. Entrevista concedida a Iomara Scandelari Lemos, José Roberto Frega, Alceu Souza, Wesley Vieira da Silva em dezembro de 2006.

GIL, A. C. Métodos e técnicas de pesquisa social. 5. ed. São Paulo: Atlas, 1999.
GONZALEZ, M. V. Valor econômico de visitação do Parque "Phillipe Westin Cabral de Vasconcelos". 2004. 126 f. Dissertação (Mestrado em Programa de Pós-Graduação em Ciências: Economia Aplicada) Universidade de São Paulo, Piracicaba, 2004.

HANLEY, N. D.; SPASH, C. L. Cost-benefit analysis and the environment. 2nd. ed. Cheltenham: Edward Elgar Publishing, 1993.

HUFSCHMIDT, M. M. et al. Environment, natural systems, and development: an economic valuation guide. 2nd. ed. Baltimore: Johns Hopkins Univ. Press, 1983.

LAKATOS, E. M.; MARCONI, M. A. Metodologia científica. 3. ed. São Paulo: Atlas, 2000.

LEMOS, L. O valor turístico na economia da sustentabilidade. 3. ed. São Paulo: Aleph, 2005.

LEMOS, I.S.;FREGA, J. R.;SOUZA, A. Um framework para a avaliação da estratégia do arranjo produtivo local para o turismo: o caso de Treze Tílias. Turismo Visão e Ação, v. 9, n. 1, p. 41, 2007.

MARTINS, E. C. O turismo como alternativa de desenvolvimento sustentável: o caso de Jericoacoara no Ceará. 2002. 204 f. Tese (Doutorado em Ciências: Economia Aplicada) - Universidade de São Paulo, Piracicaba, 2002. Disponível em: <http://www.teses.usp.br>. Acesso em: $11 \mathrm{dez} .2006$.

MARTINS,E.C.;PERES,F.C. Oturismo como alternativa de desenvolvimento sustentável: o caso de Jericoacoara no Ceará. Revista Econômica do Nordeste, v. 36, n. 2, p. 56-61, 2005.

PEARCE, D. W. Economic values and the natural world. 2nd ed. London: Earthscan, 1993.

PINDYCK, R. S.; RUBINFELD, D. L. Microeconomia. 2. ed. São Paulo: Makron Books, 1994.

TRIVIÑOS, A. N. S. Introduçãoà pesquisa em ciências sociais: a pesquisa qualitativa em educação. $O$ positivismo, a fenomenologia, o marxismo. 3. ed. São Paulo: Atlas, 1987.

YOUNG, C. E. F.; FAUSTO, J. R. B. Valoração de recursos naturais como instrumento de análise da expansão da fronteira agrícola na Amazônia. Rio de Janeiro: Instituto de Pesquisa Econômica Aplicada. Texto para Discussão, 490. Disponível em: < http://www.niead. ufrj.br>. Acesso em: 12 dez. 2006.

Recebido: 14/06/2007 Received: 06/14/2007

Aprovado: 10/08/2007 Approved: 08/10/2007 